\title{
Effects of dexmedetomidine in reducing post-cesarean adverse reactions
}

\author{
YANSHUAI MO and SHUANG QIU \\ Department of Anesthesiology, Linyi People's Hospital, Linyi, Shandong 276003, P.R. China
}

Received April 7, 2017; Accepted June 30, 2017

DOI: $10.3892 /$ etm.2017.4759

\begin{abstract}
This study evaluated the analgesia effect and the effect on adverse reaction of using dexmedetomidine (Dex) in post-cesarean section. Eighty women who had been performed caesarean delivery with combined spinal and epidural anesthesia were selected. The experimental group (group D) included 40 random patients and the control group (group C) included the other 40 women. Patients in group D were given ropivacaine hydrochloride and Dex while patients in group $\mathrm{C}$ were given ropivacaine hydrochloride and morphine. We assessed and recorded the patient status at 2, 6, 12,24 and $48 \mathrm{~h}$ using Ramsay sedation scale and visual analogue scale (VAS) in resting state and coughing state and we also recorded their adverse reactions. Except for the first $2 \mathrm{~h}$ after surgery, group D gets a lower VAS score than group $\mathrm{C}$ all the time in either resting state or coughing state $(\mathrm{p}<0.05)$; at $12 \mathrm{~h}$, group D had a lower Ramsay score than group $\mathrm{C}(\mathrm{p}<0.05)$ and no significant difference during the rest of the time was found; group D had a significantly lower rate of nausea, emesis and pruritus than group $\mathrm{C}(\mathrm{p}<0.05)$. In conclusion, the usage of Dex in analgesia for post-cesarean can increase the analgesia effect produced by local anesthetics, increase puerpera sedation scores and decrease adverse reactions.
\end{abstract}

\section{Introduction}

In China, 50-60\% of pregnant women give birth via cesarean section. Puerpera undergo different levels of pain. Clinically, great pain after cesarean section could bring patients nausea, pruritus, intestinal peristalsis slowness, muscle spasms, thromboembolism, cardiopulmonary complications and incision healing delay and such a series of physiological changes have great impacts on puerpera's postpartum physiological functions and mental state and even on postpartum recuperation

Correspondence to: Dr Shuang Qiu, Department of Anesthesiology, Linyi People's Hospital, 27 East Jiefang Road, Linyi, Shandong 276003, P.R. China

E-mail: czotkk@163.com

Key words: dexmedetomidine, caesarean section, adverse reactions, patient-controlled epidural analgesia and breast-feeding. The choice of anesthesia for post-caesarean section is always a clinical hot spot. A good postoperative analgesia will greatly relieve puerpera's pains, provide good conditions for purepera to recuperate and get out of bed and also for caring for and breast-feeding newborns (1).

Nowadays, clinical choices of anesthesia for post-caesarean section usually are: Intraductal route of administration, single intrathecal injection of opioids, single epidural injection of opioids and persistent epidural analgesia; administration by intravenous route. Results from Rapp-Zinggraff et al shows that the group with patient-controlled intravenous analgesia has a significant higher visual analogue scale VAS score than the group with epidural analgesia (1). Another investigation shows that the usage of pethidine in patient-controlled intravenous analgesia after caesarean section can decrease the alertness of breastfeeding newborns and weaken their directional response (2). Compared to epidural anesthesia, wound infiltration has weaker analgesic effect although it can be used in post-caesarean section $(3,4)$. Oral analgesic has many advantages, such as good compliance, convenience and good analgesic effect, but it is usually used as ancillary drug or instant analgesic method when analgesic effect fails its expectation. Patient-controlled epidural analgesic (PCEA) is the first choice of anesthesia methods for post-caesarean section.

Combining opioid with local anesthetics is the most common formulation on epidural space for caesarean section, since it can produce synergistic effect, and enhance analgesic effect. However, its adverse reactions are nausea, emesis, shiver, cutaneous pruritus and urinary retention. Hence, a new drug with good analgesic effect and less adverse reaction needs to be found. Clinical studies have shown that dexmedetomidine (Dex) intrathecal injection is a safe application of ancillary drug used for analgesic, sedation, prevention of shiver in anesthetic for post-caesarean section. Dex is a new high selective $\alpha 2$ adrenergic agonist. Its binding ratio of adrenergic receptor $\alpha 2$ and $\alpha 1$ is 1,620:1 (5). It is used for analgesic sedation and antisympathetic with little respiratory depression (6). Kanazi et al showed that Dex intrathecal injection significantly enhance the analgesic effect of local anesthetic (7). Yoshitomi et al in their research on male guinea pig showed that the intrathecal injection used to enhance the analgesic effect of local anesthetic is via the agonist $\alpha 2 \mathrm{~A}$ receptor (8). Dex acts on the $\alpha 2$ adrenergic receptor in the locus coeruleus, activates endogenous sleep-promoting pathway and mediates physiological sedative hypnotic effect (9). Many studies show that Dex can be used 
to prevent shiver caused by spinal epidural anesthesia but its concrete mechanism is unknown. Phan and Nahata considered that Dex prevented shiver via inhibition of brain thermoregulatory center, lowering shiver threshold and affecting thermoregulatory pathway at the spinal cord level (10-13).

Applying Dex in anesthetic for post-caesarean section has a certain clinic value, but the impact on puerpera of applying Dex in PCEA for post-caesarean section is rarely reported. This study investigated the effectiveness and safety of the usage of Dex in anesthesia for post-caesarean section by observing puerpera's analgesic condition in patients who received PCEA for post-caesarean section.

\section{Patients and methods}

Research data and grouping. A total of 80 cases were divided into experimental group (group D) and control group (group C) (40 cases in each group). All the patients were administered combined spinal and epidural anesthesia for post-caesarean section. Inclusion criteria: i) Puerpera has no mental/neurological diseases, no motion sickness, no diabetes, no cardiopulmonary liver or kidney dysfunction; ii) puerpera has no sedative analgesics, no antidepressants, no corticosteroids and vasoactive drugs, medication history; and iii) newborn has no observable congenital disease. Exclusion criteria: i) Epidural catheter prolapse; ii) puerpera stops epidural continuous analgesia half-way; iii) puerpera has severe allergic reactions; and iv) puerpera has total spinal anesthesia and other serious complications. This study was approved by the Ethics Committee of Linyi People's Hospital. Signed written informed consents were obtained from all participants before the study.

Analgesic methods. Puerpera in both groups were administered patient-controlled epidural anesthesia and injected loading dose via epidural catheter after suturing the skin. We connected epidural catheter to epidural infusion pump and reinforced the joints with medical tape at the end of operation. We guided puerpera the usage of PCEA. PCEA drug formulations: Group D: Dex $1 \mu \mathrm{g} / \mathrm{kg}+0.15 \%$ ropivacaine hydrochloride $+0.9 \%$ normal saline, a total amount of $100 \mathrm{ml}$; group C: morphine $5 \mathrm{mg}+0.15 \%$ ropivacaine hydrochloride $+9 \%$ normal saline, a total amount of $100 \mathrm{ml}$. All drugs were purchased from Yangze River Pharma (Taizhou, China). This study adopted load dose + background dose + principal component analysis (PCA) model. Group D loading dose was $0.1 \mu \mathrm{g} / \mathrm{kg}$ Dex. Group C loading dose was $2 \mathrm{mg}$ morphine. Both were diluted to $5 \mathrm{ml}$ with $0.9 \%$ normal saline. Background dose was $2 \mathrm{ml} / \mathrm{h}$. One press will release a dose of $0.5 \mathrm{ml}$, locking time $15 \mathrm{~min}$ and continuous analgesia for $48 \mathrm{~h}$. When puerpera's mean arterial pressure was less than $60 \mathrm{mmHg}$, intravenous injection of $10 \mathrm{mg}$ ephedrine hydrochloride was performed; when heart rate was less than $50 \mathrm{bpm}$, intravenous injection of 0.2 atropine sulfate was performed.

Assess scales

VAS scale. VAS was used to assess the pain level of puerpera after caesarean section. We recorded their scores (both resting state and coughing state) at 2, 6, 12, 24 and $48 \mathrm{~h}$ after the operation. VAS score: 10 points method. 0, no pain; 1-3, annoying pain; 4-6, dreadful pain; 7-10, agonizing pain.
Table I. The comparison of patient characteristics between groups $\mathrm{C}$ and $\mathrm{D}$ (mean $\pm \mathrm{SD})$.

\begin{tabular}{lcccc}
\hline Groups & Cases & Age (years) & Height $(\mathrm{cm})$ & Weight $(\mathrm{kg})$ \\
\hline C & 40 & $28.6 \pm 1.3$ & $158.4 \pm 5.2$ & $68.6 \pm 2.9$ \\
D & 40 & $28.2 \pm 0.9$ & $160.1 \pm 1.9$ & $67.9 \pm 2.7$ \\
\hline
\end{tabular}

Ramsey sedation score. Ramsey Sedation Scale was used to assess the sedation level of puerpera after caesarean section. We recorded their scores at 2, 6, 12, 24 and $48 \mathrm{~h}$, after puerpera was back on the ward. Ramsey Sedation Scale: Ramsey 1, anxious, agitated and restless; Ramsey 2, cooperative, oriented and tranquil; Ramsey 3, responsive to commands only; Ramsey 4, brisk response to light glabellar tap or loud auditory stimulus; Ramsey 5, sluggish response to light glabellar tap or loud auditory stimulus; Ramsey 6, no response to light glabellar tap or loud auditory stimulus.

Adverse reaction. We recorded all the adverse reactions after puerpera recovered, such as nausea, emesis, shiver, cutaneous pruritus and respiratory depression (respiratory rate was less than $8 \mathrm{bpm}$ ) and hypotension (MAP decreased by $20 \%$ of the basic value).

Statistical analysis. SPSS 13.0 (SPSS, Inc., Chicago, IL, USA) statistical software was used. Normal distribution of measurement data is denoted as mean $\pm \mathrm{SD}$. Comparison between groups adopts two-sample t-test and one-way ANOVA. Count data adopts $\chi^{2}$ test. $\mathrm{p}<0.05$ was considered statistically significant.

\section{Results}

General information. There is no statistically significant difference in age, height and weight between the two groups (p>0.05) (Table I).

VAS score. Compared with group C, group D had lower VAS score (resting state or coughing state) $(\mathrm{p}<0.05)$ at $6,12,24$ and $48 \mathrm{~h}$ after operation and there was no significant statistical difference between two groups at $2 \mathrm{~h}(\mathrm{p}>0.05)$ (Tables II and III, Figs. 1 and 2).

Ramsay score. Compared with group C, group D had significantly higher Ramsay score at $12 \mathrm{~h}(\mathrm{p}<0.05)$ after operation, and there was no significant statistical difference between the two groups at 2, 6, 24 and $48 \mathrm{~h}$ (p>0.05) (Table IV, Fig. 3).

Incidence of adverse reactions. The incidence of nausea, emesis and pruritus in group D was significantly less than that in group $\mathrm{C}(\mathrm{p}<0.05)($ Table V). The incidence of chills, respiratory depression and hypotension was not statistically significant $(\mathrm{p}>0.05)$.

\section{Discussion}

Pain will stimulate puerpera sympathetic nerve, increase catecholamine and the secretion of metabolic hormone. Thereby this will increase the body oxygen consumption and then affect the body's digestive function, physical recovery, 
Table II. The comparison of VAS score between groups $\mathrm{C}$ and $\mathrm{D}$ at each point (the resting state) (mean $\pm \mathrm{SD})$.

\begin{tabular}{lccccc}
\hline Groups & $2 \mathrm{~h}$ & $6 \mathrm{~h}$ & $12 \mathrm{~h}$ & $24 \mathrm{~h}$ & $48 \mathrm{~h}$ \\
\hline $\mathrm{D}$ & $0.91 \pm 0.6$ & $1.62 \pm 0.5^{\mathrm{a}}$ & $3.6 \pm 0.5^{\mathrm{a}}$ & $3.5 \pm 0.7^{\mathrm{a}}$ & $1.92 \pm 0.8^{\mathrm{a}}$ \\
$\mathrm{C}$ & $0.91 \pm 0.6$ & $2.2 \pm 0.6$ & $4.5 \pm 1.3$ & $4.2 \pm 0.9$ & $3.1 \pm 0.8$ \\
\hline
\end{tabular}

${ }^{\mathrm{a}} \mathrm{p}<0.05$ vs. group $\mathrm{C}$.

Table III. The comparison of VAS score between groups $\mathrm{C}$ and $\mathrm{D}$ at each point (The cough state) (mean $\pm \mathrm{SD}$ ).

\begin{tabular}{|c|c|c|c|c|c|}
\hline Groups & $2 \mathrm{~h}$ & $6 \mathrm{~h}$ & $12 \mathrm{~h}$ & $24 \mathrm{~h}$ & $48 \mathrm{~h}$ \\
\hline D & $0.91 \pm 0.6$ & $3.8 \pm 0.5^{\mathrm{a}}$ & $6.3 \pm 0.5^{\mathrm{a}}$ & $5.5 \pm 0.7^{\mathrm{a}}$ & $4.2 \pm 0.8^{\mathrm{a}}$ \\
\hline $\mathrm{C}$ & $1.1 \pm 0.6$ & $5.6 \pm 0.6$ & $7.2 \pm 1.3$ & $6.2 \pm 0.9$ & $5.1 \pm 0.8$ \\
\hline
\end{tabular}

${ }^{\mathrm{a}} \mathrm{p}<0.05$ vs. group $\mathrm{C}$.

Table IV. The comparison of Ramsay scale between group C and $\mathrm{DF}$ at each point (mean $\pm \mathrm{SD}$ ).

\begin{tabular}{lccccc}
\hline Groups & $2 \mathrm{~h}$ & $6 \mathrm{~h}$ & $12 \mathrm{~h}$ & $24 \mathrm{~h}$ & $48 \mathrm{~h}$ \\
\hline $\mathrm{D}$ & $2.7 \pm 0.6$ & $2.6 \pm 0.5$ & $4.2 \pm 0.5^{\mathrm{a}}$ & $2.9 \pm 0.7$ & $2.7 \pm 0.8$ \\
$\mathrm{C}$ & $2.4 \pm 0.6$ & $2.6 \pm 0.6$ & $3.6 \pm 1.3$ & $2.8 \pm 0.9$ & $2.6 \pm 0.8$ \\
\hline
\end{tabular}

${ }^{\mathrm{a}} \mathrm{p}<0.05$ vs. group $\mathrm{C}$.

causing puerpera mood swings, depression, irritability and other negative emotions, seriously affecting puerpare sleeping, diet, delaying puerpera rehabilitation and even inhibiting lactation. Secondly, if the acute pain after cesarean section is not well ontrolled, it is likely to be converted into chronic pain. In western countries, there is an increasing rate of acute pain after cesarean section being converted into chronic pain (14).

Morphine, as a classical epidural analgesic drug, has unique characteristics: Good analgesic effect, economical and convenient. Researches showed that morphine can enter the cerebrospinal fluid, bind with opioid receptor at spinal cord dorsal horn glial area and thus result in potent and lasting analgesic effect (15). However, morphine is reported to be able to stimulate the $\mu$ receptor, slow down gastrointestinal emptying, increase gastric antrum and duodenal smooth muscle tension and stimulate the opioid receptor of emesis chemoreceptor which leads to nausea, and emesis. Morphine can also promote the release of histamine and cause pruritus.

Dex is high fat-soluble and it can reach the subarachnoid space through spinal needle hole and dispersion and directly work on $\alpha 2$ adrenergic receptor which is on the presynaptic membrane and posterior membrane of spinal cord neurons. Then it inhibits the release of adrenaline and hyperpolarizes cell membrane which reduces the release of sensory neurotransmitters (such as substance P, norepinephrine) and

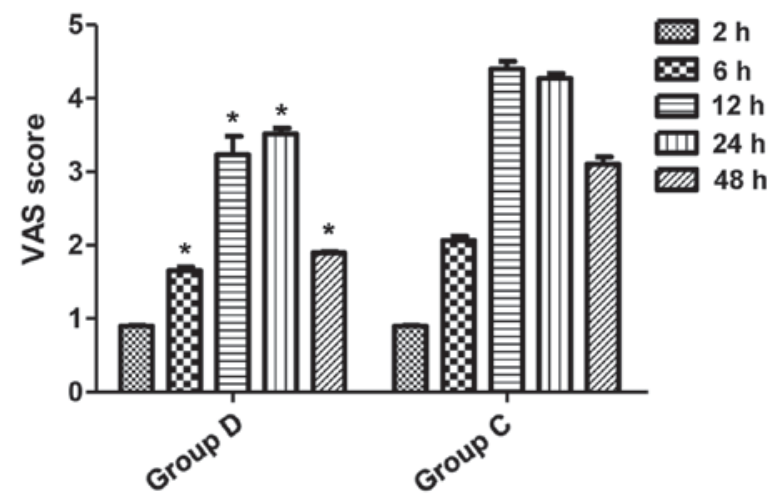

Figure 1. The comparison of VAS score between group D and $\mathrm{C}$ at each point in resting state. We recorded VAS scores at 2, 6, 1224 and $48 \mathrm{~h}$ after the operation. ${ }^{*} \mathrm{P}<0.05$. VAS, visual analogue scale.

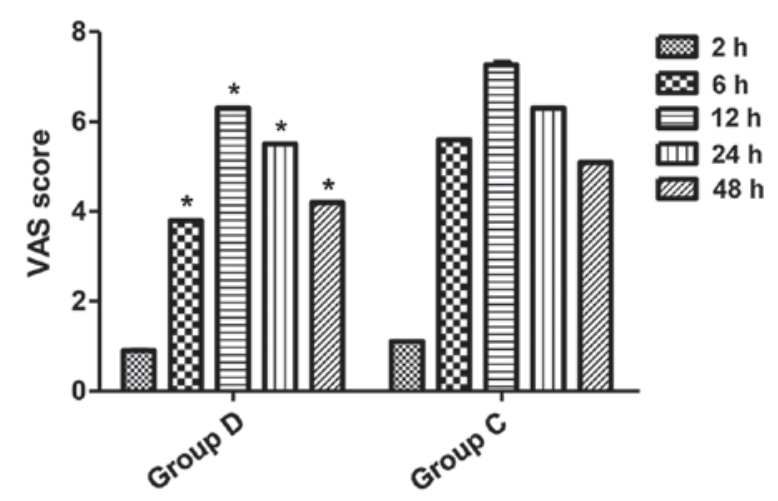

Figure 2. The comparison of VAS score between group D and $\mathrm{C}$ at each point in cough state. We recorded VAS scores at 2, 6, 12, 24 and $48 \mathrm{~h}$ after the operation. ${ }^{*} \mathrm{P}<0.05$. VAS, visual analogue scale.

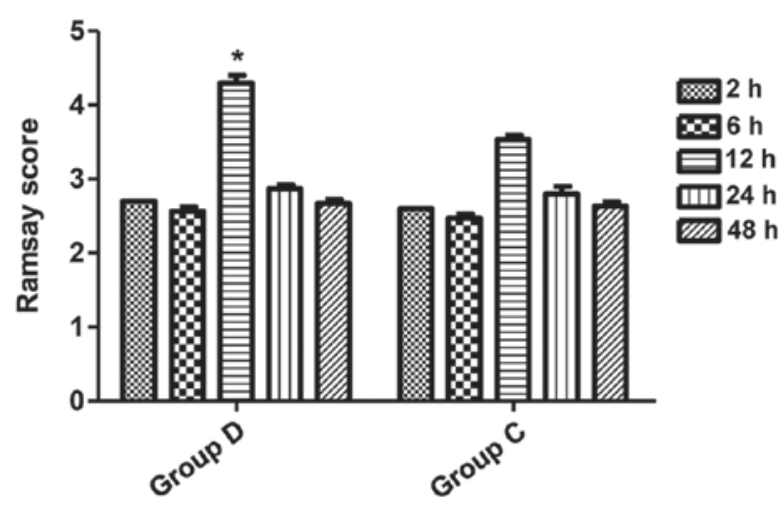

Figure 3. The comparison of Ramsey score between group D and C. We recorded their Ramsey scores at 2, 6, 12,24 and $48 \mathrm{~h}$ after puerpera was back on the ward. ${ }^{*} \mathrm{P}<0.05$.

inhibits the transmission of nociceptive information $(13,16)$. We found in both resting state and in coughing state, group D had a lower VAS score than group C at 6, 12, 24 and $48 \mathrm{~h}$ after operation. Possible causes are that Dex directly works on epispinal $\alpha 2$ adrenergic receptor through spinal needle hole and dispersion effect, inhibiting the transmission of pain information; Dex has a synergistic effect with ropivacaine hydrochloride, enhances analgesic effect and thus lowers puerpera VAS score. No statistical difference between two groups 
Table V. The comparison of adverse effect between the groups C and D.

\begin{tabular}{|c|c|c|c|c|c|c|}
\hline Groups & Nausea, n (\%) & Vomit, n (\%) & Shakes, n (\%) & Pruritus, n (\%) & Respiration inhibition & Hypotension \\
\hline $\mathrm{D}$ & $3(15)^{\mathrm{a}}$ & $0^{\mathrm{a}}$ & $2(5.0)$ & $2(5.0)^{\mathrm{a}}$ & 0 & 0 \\
\hline $\mathrm{C}$ & $15(37.5)$ & $6(15.0)$ & $3(7.5)$ & $11(27.5)^{\mathrm{a}}$ & 0 & 0 \\
\hline
\end{tabular}

${ }^{\mathrm{a}} \mathrm{p}<0.05$ vs. group $\mathrm{C}$.

at $2 \mathrm{~h}$ after operation is probably because the spinal anesthesia has not subsided and the puerpera in two groups are still in anesthesia at $2 \mathrm{~h}$ after operation. Group D got significant higher Ramsay score than group $\mathrm{C}$ at $12 \mathrm{~h}$ after operation is probably because that Dex can directly work on locus coeruleus nucleus via cerebrospinal fluid; puerpera in group D have a better analgesic effect and thus better rest, so they had higher Ramsay scores. In this study, incidence of nausea, emesis in group D was significantly lower than group C and possible mechanisms are: Group D adopts Dex in combined local anesthetics for analgesia rather than morphine; Dex directly work on the $\alpha 2$ receptor and imidazoline receptor in the center and other parts (17); high concentration of catecholamine may induce nausea and emesis, and Dex can reduce the sympathetic tension and the release of catecholamine, thereby reduce the incidence of nausea and emesis. Incidence of pruritus of group D was significantly lower than group C, and it may result from substituting Dex for morphine in PCEA. Adopting Dex after caesarean section does not induce bradycardia, respiratory depression or hypotension.

Therefore, we concluded that the usage of Dex in continuous patient-controlled epidural anesthetics after cesarean section can product a good synergistic effect with local anesthetic drugs and enhance analgesic effect, reducing the incidence of nausea, emesis and pruritus.

\section{References}

1. Rapp-Zingraff N, Bayoumeu F, Baka N, Hamon I, Virion JM and Laxenaire MC: Analgesia after caesarean section: Patientcontrolled intravenous morphine vs epidural morphine. Int J Obstet Anesth 6: 87-92, 1997.

2. Wittels B, Scott DT and Sinatra RS: Exogenous opioids in human breast milk and acute neonatal neurobehavior: A preliminary study. Anesthesiology 73: 864-869, 1990.

3. Fredman B, Shapiro A, Zohar E, Feldman E, Shorer S, Rawal N and Jedeikin R: The analgesic efficacy of patient-controlled ropivacaine instillation after Cesarean delivery. Anesth Analg 91: 1436-1440, 2000.

4. Ranta PO, Ala-Kokko TI, Kukkonen JE, Ohtonen PP, Raudaskoski TH, Reponen PK and Rawal N: Incisional and epidural analgesia after caesarean delivery: A prospective, placebo-controlled, randomised clinical study. Int J Obstet Anesth 15: 189-194, 2006.
5. Lee JH, Kim H, Kim HT, Kim MH, Cho K, Lim SH, Lee KM, Kim YJ and Shin CM: Comparison of dexmedetomidine and remifentanil for attenuation of hemodynamic responses to laryngoscopy and tracheal intubation. Korean J Anesthesiol 63: 124-129, 2012.

6. Hanci V, Erdoğan G, Okyay RD, Yurtlu BS, Ayoğlu H, Baydilek Y and Turan IO: Effects of fentanyl-lidocaine-propofol and dexmedetomidine-lidocaine-propofol on tracheal intubation without use of muscle relaxants. Kaohsiung J Med Sci 26: 244-250, 2010.

7. Kanazi GE, Aouad MT, Jabbour-Khoury SI, Al Jazzar MD, Alameddine MM, Al-Yaman R, Bulbul M and Baraka AS: Effect of low-dose dexmedetomidine or clonidine on the characteristics of bupivacaine spinal block. Acta Anaesthesiol Scand 50: 222-227, 2006.

8. Yoshitomi T, Kohjitani A, Maeda S, Higuchi H, Shimada M and Miyawaki T: Dexmedetomidine enhances the local anesthetic action of lidocaine via an alpha-2A adrenoceptor. Anesth Analg 107: 96-101, 2008.

9. Hu R, Liu JX and Jiang H: Dexmedetomidine versus remifentanil sedation during awake fiberoptic nasotracheal intubation: A double-blinded randomized controlled trial. J Anesth 27: 211-217, 2013.

10. Phan $\mathrm{H}$ and Nahata MC: Clinical uses of dexmedetomidine in pediatric patients. Paediatr Drugs 10: 49-69, 2008.

11. Abdalla MI, Al Mansouri F and Bener A: Dexmedetomidine during local anesthesia. J Anesth 20: 54-56, 2006.

12. GertlerR,BrownHC,MitchellDH,SilviusEN.Dexmedetomidine: a novel sedative-analgesic agent. Proc (Bayl Univ Med Cent) 14: 13-21, 2001.

13. Neumann MM, Davio MB, Macknet MR and Applegate RL II: Dexmedetomidine for awake fiberoptic intubation in a parturient with spinal muscular atrophy type III for cesarean delivery. Int J Obstet Anesth 18: 403-407, 2009.

14. Perkins FM and Kehlet H: Chronic pain as an outcome of surgery. A review of predictive factors. Anesthesiology 93: 1123-1133, 2000 .

15. Kralovec J: Mighty morphin' materials management. Mater Manag Health Care 10: 16-19, 2001.

16. Ishii H, Kohno T, Yamakura T, Ikoma M and Baba H: Action of dexmedetomidine on the substantia gelatinosa neurons of the rat spinal cord. Eur J Neurosci 27: 3182-3190, 2008.

17. Oddby-Muhrbeck E, Eksborg S, Bergendahl HT, Muhrbeck O and Lönnqvist PA: Effects of clonidine on postoperative nausea and vomiting in breast cancer surgery. Anesthesiology 96: 1109-1114, 2002. 